\title{
Studies on the Rumen Flagellate Sphaeromonas communis
}

\author{
By C. G. ORPJ N \\ Department of Biochemistry, A.R.C. Institute of Animal Physiology, \\ Babraham, Cambridge CB2 $4 A T$
}

(Received 20 October 1975)

SUM M AR Y

The rumen flagellate Sphaeromonas communis showed a significant increase in population density I to $2 \mathrm{~h}$ after the host sheep commenced feeding, followed by a reduction in numbers to the pre-feeding level after a further 2 to $3 \mathrm{~h}$. The lifehistory of the organism was shown to consist of a motile flagellate which germinated to produce a vegetative stage comprising a limited rhizoidal system on which up to three reproductive bodies were borne together with (in vitro) other spherical bodies of unknown function; in vivo, the reproductive bodies were stimulated to liberate flagellates by a component of the diet of the host. The vegetative stage strongly resembled that of certain species of aquatic phycomycete fungi, and the flagellates may therefore be zoospores. Flagellates liberated in vivo lost their motility within 2 to $3 \mathrm{~h}$ and developed into the reproductive vegetative phase, producing a rapid decrease in numbers of flagellates. Conditions of maximum flagellate production ( $\mathrm{pH} \mathrm{6.5}, 39{ }^{\circ} \mathrm{C}$, presence of $\mathrm{CO}_{2}$, absence of oxygen) approximated to those found in the rumen. The organism was cultured in vitro in an undefined medium in the absence of bacteria and other flagellates.

\section{INTRODUCTION}

Rumen flagellates possessing a spherical-to-ovoid cell and a single flagellum were described by Liebetanz (1910) and by Braune (1913). Since then, very few references to this type of organism have been made in the literature, and no mention was made by Hungate ( 1966) or by Jensen \& Hammond (1964). It appears that the organisms have been overlooked, perhaps from lack of knowledge of their identity, even though population densities of $10^{5} \mathrm{ml}^{-1}$ have been recorded for flagellates with this morphology in the sheep at the author's laboratory. Both Liebetanz (1910) and Braune (1913) regarded them as flagellate protozoa, an opinion also held by Das Gupta (1935) and Becker \& Talbot (1927). Four genera of these rumen flagellates have been named - Monas, Sphaeromonas, Piromonas and Oikomonas but they were subsequently thought to be synonymous (Braune, 1913; Wenyon, 1926; Das Gupta, 1935; Levine, 196I). However, no mention was made by Kudo (1954) of representatives of Monas or Oikomonas occurring in the rumen, and the genera Sphaeromonas and Piromonas were not included in his treatise. Since the flagellates described herein fit most closely the description by Braune (1913) of Sphaeromonas communis Liebetanz, I have used this nomenclature.

Organisms resembling phycomycete fungi free-living in the rumen were first reported by Orpin (1975), who found that the rumen flagellate Neocallimastix frontalis was probably a zoospore of a phycomycete fungus and not a flagellate protozoon as previously believed (Braune, I9I3). The vegetative phase morphologically resembled aquatic Phycomyces. These investigations were prompted by the observation (Warner, 1966) that the flagellate stages of $N$. frontalis underwent considerable fluctuations in population density over the feeding 
period of the host animal. During Orpin's investigations the population density of flagellates possessing a single flagellum fluctuated over the feeding period of the host animal, but to a lesser degree than that of $N$. frontalis zoospores. A second type of reproductive body was detected which developed to produce large numbers of flagellates morphologically identical with $S$. communis Liebetanz (Orpin, 1974b), and it is this organism and its life-history which is the subject of this paper.

\section{METHODS}

Animals. The sheep used were Clun Forest wethers, each fitted with a permanent rumen cannula and fed once daily with $800 \mathrm{~g}$ hay chaff and $200 \mathrm{~g}$ crushed oats. Defaunation was by a modification of the method of Abou Akkada et al. (1968); $10 \mathrm{~g}$ of dioctyl sodium sulphosuccinate was administered through the rumen cannula and food withheld on day I; on day 2 a further Io $\mathrm{g}$ of dioctyl sodium sulphosuccinate was added and only hay chaff fed. Feeding of the normal diet was resumed on the third day.

Sampling and counting. Samples of rumen fluid were taken by aspiration, and the sphaeromonas flagellates and sporangia counted as described by Orpin (1974a) for $N$. frontalis. Sporangia of $S$. communis were differentiated from those of Neocallimastix by incubation at $39^{\circ} \mathrm{C}$ with inducer (Orpin, 1974a) for $30 \mathrm{~min}$, when all neocallimastix sporangia differentiated and ruptured. The remaining sporangia were those of Sphaeromonas. Samples were taken from in vitro experiments after thorough mixing, and sphaeromonas organisms or sporangia counted.

Rumen fluid. The rumen fluid used both for in vitro experiments and for counting populations after growth in vivo was strained through one layer of muslin before use, and designated FRF. The maximum particle size present after straining was $550 \mu \mathrm{m}$. The material retained was designated the coarse food particle (CFP) fraction. For all in vitro experiments, FRF originating from defaunated sheep was used, since the absence of ciliate protozoa facilitated the counting of both sporangia and $S$. communis flagellates. FRF was centrifuged at $1000 \mathrm{~g}$ for I $5 \mathrm{~min}$ at room temperature and the sediment washed twice with and suspended in CRF (see below). This fraction was designated the large particulate (LP) fraction. The supernatant of the centrifuged rumen fluid was then centrifuged at $20000 \mathrm{~g}$ for $\mathrm{I} h$ at $2{ }^{\circ} \mathrm{C}$ : this supernatant was designated centrifuged rumen fluid (CRF).

Extraction of inducer. The stimulatory component of oats was extracted by the method used by Orpin ( $1974 a$ ). The volume of the final aqueous extract was adjusted so that $\mathrm{I} \mathrm{ml}$ represented the extract from I $\mathrm{g}$ dry wt of oats. This extract was stored at $-20^{\circ} \mathrm{C}$, and is the 'inducer' referred to in this paper. Inducer was also extracted similarly from the CFP fraction of rumen fluid, after that fraction had been washed twice with water $(20 \mathrm{ml} / \mathrm{g}$ wet wt of CFP) on the filter.

Assay in vitro for sphaeromonas flagellate production. FRF ( $1.0 \mathrm{ml})$ was incubated with ०. I ml of inducer in a stoppered, $\mathrm{CO}_{2}$-gassed test-tube, in a water bath at $39^{\circ} \mathrm{C}$. The population density was determined initially and after $\mathrm{I} h$, and compared with a blank tube containing $0.1 \mathrm{ml}$ of water instead of inducer.

Experiments with different gas phases. These were conducted in the same manner using the standard assay techniques, except that the FRF was bubbled with the experimental gas for 2 min before addition of the inducer. The tube was then stoppered and incubated under the gas phase.

Experiments with $\mathrm{pH}$ variation. These were conducted after the addition of a predetermined quantity of $0 \cdot \mathrm{I} \mathrm{M}-\mathrm{HCl}$ or ${ }^{0} \cdot \mathrm{I} \mathrm{M}-\mathrm{NaOH}$ to bring the $\mathrm{FRF}$ to the required $\mathrm{pH}$. 
Experiments with temperature variation. Tubes containing the standard assay materials were prepared as described before and incubated under $\mathrm{CO}_{2}$ in water baths at the desired temperatures.

Environmental examination. Samples of diet and of the sawdust used for bedding were washed with $67 \mathrm{~mm}$-sodium phosphate buffer $\mathrm{pH} \mathrm{6.5}$, and the washings centrifuged at $2500 \mathrm{~g}$ for $5 \mathrm{~min}$. The sediment was examined microscopically to determine whether sphaeromonas flagellates or sporangia were present. The water in the water trough was centrifuged and examined similarly.

Culture in vitro. The following medium (all quantities are given as $w / v$ in water, unless otherwise stated) was allowed to gel in a $12.5 \times \mathrm{I} \cdot 25 \mathrm{~cm}\left(5 \times \frac{1}{2}\right.$ in) rimless test tube and then overlaid with FRF (0.I ml): CRF, I0 \% (v/v); $\mathrm{NaHCO}_{3}, 0.65 \% ; \mathrm{K}_{2} \mathrm{HPO}_{4}, 0.64 \% ; \mathrm{KH}_{2} \mathrm{PO}_{4}$, $0.5 \%: \mathrm{NaCl}, 0.64 \% ; \mathrm{CaCl}_{2} .2 \mathrm{H}_{2} \mathrm{O}, 0.006 \% ; \mathrm{MgSO}_{4} .7 \mathrm{H}_{2} \mathrm{O}, 0.01 \% ;$ glucose, $0.02 \%$; L-cysteine hydrochloride, $0.02 \%$; streptomycin sulphate, $0.1 \%$; sodium benzyl penicillin, $100 \mathrm{u} . / \mathrm{ml}$; agar, $0.1 \%$. After 3 to 5 days' incubation at $39^{\circ} \mathrm{C}$, sphaeromonas flagellates were observed in the culture medium below the level of the particulate constituents of the overlaid rumen fluid, and quantities of medium $(0.5 \mathrm{ml})$ containing flagellates were transferred aseptically to fresh culture tubes. After 2 to 3 days' incubation at $39{ }^{\circ} \mathrm{C}$, growth was visible in the lower half of the culture tube. This growth consisted of sphaeromonas flagellates together with reproductive structures, and was free of bacteria after 3 sub-cultures. Cultures were transferred every 4 to 5 days into fresh medium either with or without antibiotics. It was necessary to include antibiotics in stock cultures.

\section{RESULTS}

\section{Observations in vivo and in vitro}

Sphaeromonas flagellates (Fig. I $a, b$ ) were found in $80 \%$ of 20 sheep examined, both in sheep with normal rumen microbial populations and in sheep whose rumens had been defaunated of ciliate protozoa. In the defaunated sheep, the total population density of flagellates - including sphaeromonas - ranged from $3.9 \times 10^{5}$ to $2.2 \times 10^{7} \mathrm{ml}^{-1}$, while in the normally faunated animals it ranged from $4.2 \times 10^{3}$ to $6.4 \times 10^{5} \mathrm{ml}^{-1}$. However, the higher number in the defaunated sheep was due to trichomonads and related flagellate protozoa, rather than $N$. frontalis or $S$. communis (Table 1), although both of the latter species were slightly more numerous in defaunated animals. During the defaunation procedure sphaeromonas flagellates disappeared from the treated rumens; they reappeared within $\mathrm{I}$ to 2 weeks and a further 2 to 3 weeks later their population density had risen to a constant level.

The population density of sphaeromonas flagellates in vivo normally showed a 3 to 6 -fold increase (rarely up to 22-fold), compared with that before feeding, within 90 min of the commencement of feeding by the host; afterwards, it dropped quickly to the pre-feeding level. A typical population density curve for a $24 \mathrm{~h}$ period is shown in Fig. 3. Although the maximum population density normally occurred 50 to 90 min after feeding, sphaeromonas flagellates were present throughout the remaining $24 \mathrm{~h}$. Apart from the fluctuation over the feeding period, no significant population density fluctuations occurred. Similar fluctuations to those recorded over the feeding period could be caused both by the addition to the rumen of inducer extracted from $300 \mathrm{~g}$ dry wt oats, and (in vitro) by the addition of $0.1 \mathrm{ml}$ inducer to $\mathrm{I} \cdot \mathrm{O} \mathrm{ml}$ FRF.

Fractionation of the rumen fluid showed that the population density increase was associated with the LP fraction of rumen fluid: when this fraction was incubated with the 

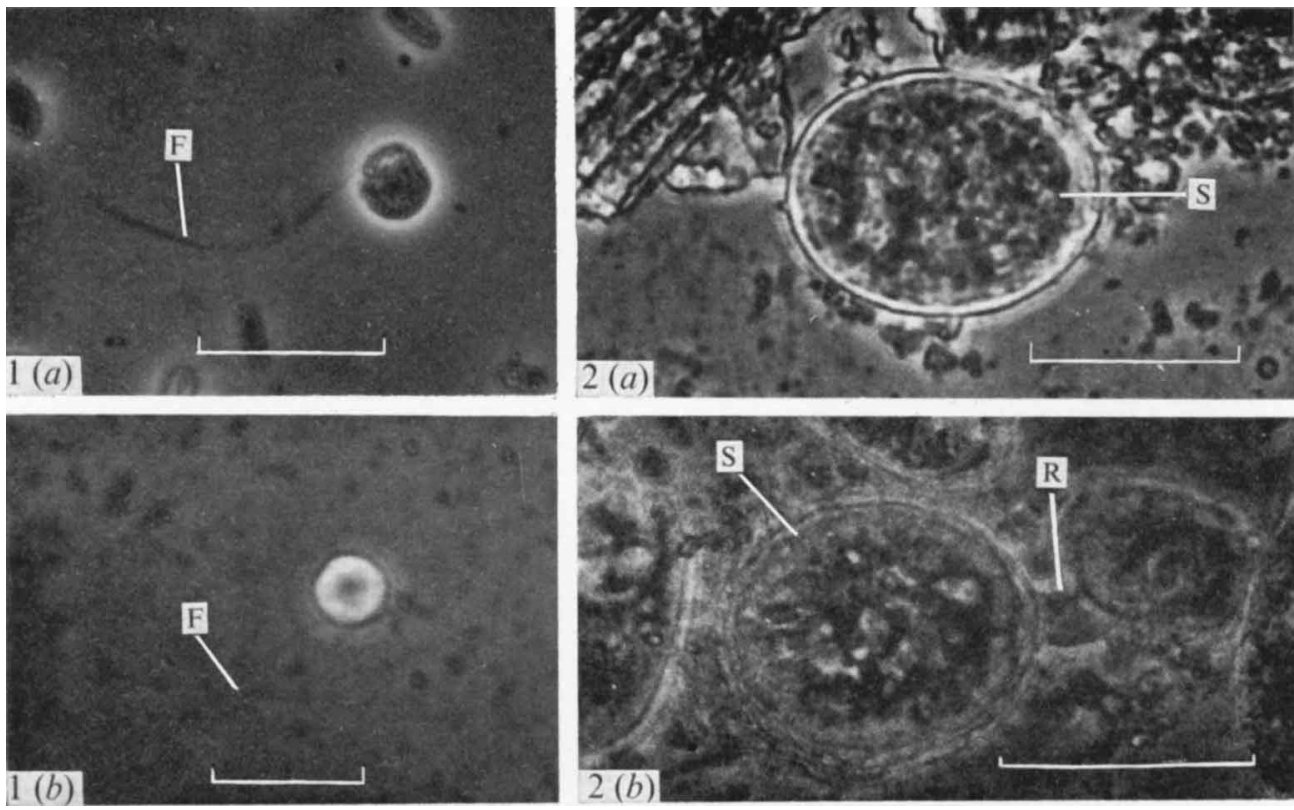

Fig. I. Sphaeromonas communis flagellate: (a) fixed in $1 \% \mathrm{HCHO}$; $(b)$ living preparation (motile). $\mathrm{F}$, flagellum. Bar marker $=20 \mu \mathrm{m}$.

Fig. 2. Sporangium of Sphaeromonas in fresh rumen fluid. (a) Sporangium without rhizoid; (b) sporangium possessing short rhizoid. S, sporangium; R, rhizoid. Bar marker $=50 \mu \mathrm{m}$.

\section{Table I. Population densities of rumen flagellates during defaunation of ciliate protozoa using dioctyl sodium sulphosuccinate}

Samples of rumen fluid were taken $23 \mathrm{~h}$ after feeding; results are averages from three sheep. On day $o$, the first day of the defaunation procedure, population densities of the flagellates were recorded before administration of dioctyl sodium sulphosuccinate.

Time after defaunation (days)

Flagellate protozoa $\left(\mathrm{IO}^{-5} \mathrm{ml}^{-1}\right)$

Neocallimastix flagellates $\left(\mathrm{IO}^{-3} \mathrm{ml}^{-1}\right)$

Sphaeromonas flagellates $\left(10^{-4} \mathrm{ml}^{-1}\right)$

$\begin{array}{cclc}-2 & 0 & 2 & 6 \\ 2 \cdot 2 & 2 \cdot 0 & 0 \cdot 2 & 4 \cdot 2 \\ 24 & 20 & 0 & 14 \\ 14 & 16 & 0 & 6\end{array}$

I4 I 6

inducer in vitro, sphaeromonas flagellates appeared in the supernatant fluid (Table 2). Microscopic examination revealed the presence of bodies resembling fungal sporangia in the LP fraction, many of which could be identified as $N$. frontalis (Orpin, 1975). Some of the larger ( $>30 \mu \mathrm{m}$ long) sporangia were more rounded in shape and more refractile than those of Neocallimastix; occasionally, a short thick appendage, possibly a rhizoid, was attached to one end of the sporangium.

\section{Evidence for the association of the sporangia with Sphaeromonas communis}

Experiments in vivo in a sheep containing both $N$. frontalis and $S$. communis revealed a 2-stage decrease in the population density of the sporangia after the addition to the rumen of inducer extracted from $300 \mathrm{~g}$ crushed oats. This quantity was sufficient to induce a $100 \%$ differentiation and release of zoospores of Neocallimastix within 15 to $30 \mathrm{~min}$ (Orpin, I975).

The decrease in number of sporangia correlated with an increase in the number of zoospores of Neocallimastix at the first stage ( 5 to $30 \mathrm{~min}$ ) and with an increase in the number 


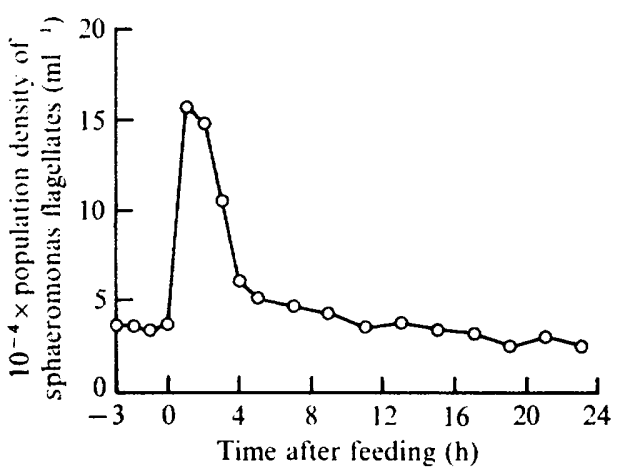

Fig. 3

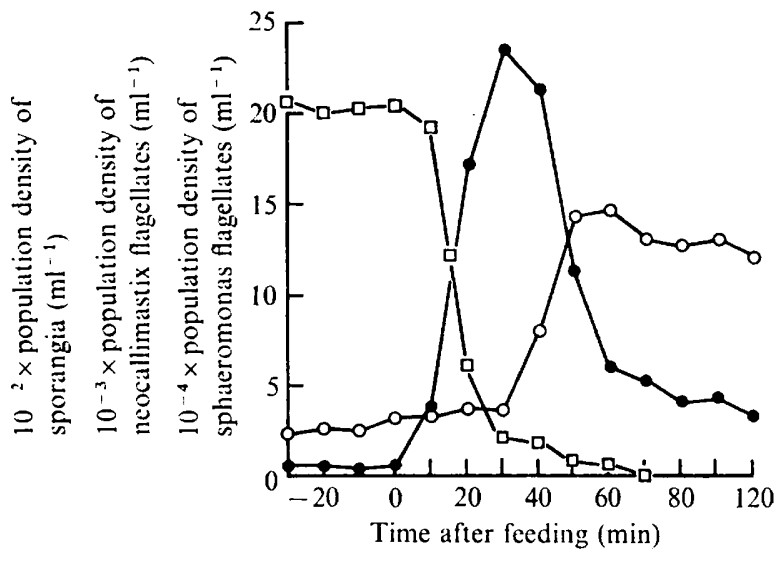

Fig. 4

Fig. 3. Population density curve for sphaeromonas flagellates throughout $24 \mathrm{~h}$. The sheep were fed at zero time. Average of three experiments.

Fig. 4. Population density curves for total sporangia ( $\square$ ) and flagellates of $N$. frontalis (๑) and $S$. communis (O). Inducer (from $300 \mathrm{~g}$ dry wt oats) was added at zero time. Average of three experiments.

Table 2. Effect of rumen fluid fractionation on the numbers of sphaeromonas flagellates; means of four experiments

Time after addition of inducer (h)

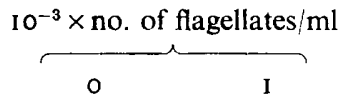

Whole rumen fluid

$>550 / \mathrm{m}$ particulate fraction

$1000 \mathrm{~g}$ sediment

$20000 \mathrm{~g}$ sediment

Supernatant

$\begin{array}{rr}0 & 1 \\ 42 & 212 \\ 0 & 0 \\ 26 & 184 \\ 0 & 0 \\ 0 & 0\end{array}$

of sphaeromonas flagellates in the second stage (45 to $60 \mathrm{~min}$ ) (Fig. 4). After $30 \mathrm{~min}$ from the time of addition of inducer, the larger sporangia remaining were mostly those previously described as being more rounded and refractile than those of $N$. frontalis (Fig. $2 a, b$ ); the smaller sporangia remaining at this stage were indistinguishable from small neocallimastix sporangia. Up to $10 \%$ of the sporangia were still present after the development of the neocallimastix sporangia.

To ascertain if the remaining sporangia were responsible for the increase in the sphaeromonas population density, LP fraction $(1.0 \mathrm{ml})$ was mixed with inducer $(0 . \mathrm{I} \mathrm{ml})$, and $0.01 \mathrm{ml}$ of this suspension was placed on a pre-heated $\left(39^{\circ} \mathrm{C}\right)$ microscope slide, sealed with Vaseline to restrict oxygen access, and placed on a heated $\left(39^{\circ} \mathrm{C}\right)$ microscope stage. The sporangia were then observed over the period when the population density increase of the sphaeromonas was expected. Within $30 \mathrm{~min}$, differentiation and release of the neocallimastix zoospores was complete; the remaining sporangia showed clear signs of internal differentiation and ultimately ruptured with the release of the sphaeromonas flagellates. After 75 min most sphaeromonas had been released from the sporangia. The development of one of these sporangia in whole rumen fluid is shown in Fig. 5. Figure 5(a) shows a sporangium at an advanced stage of internal differentiation, $45 \mathrm{~min}$ after the addition of the inducer. Figure $5(b)$ shows the same sporangium at $58 \mathrm{~min}$, when the sphaeromonas 

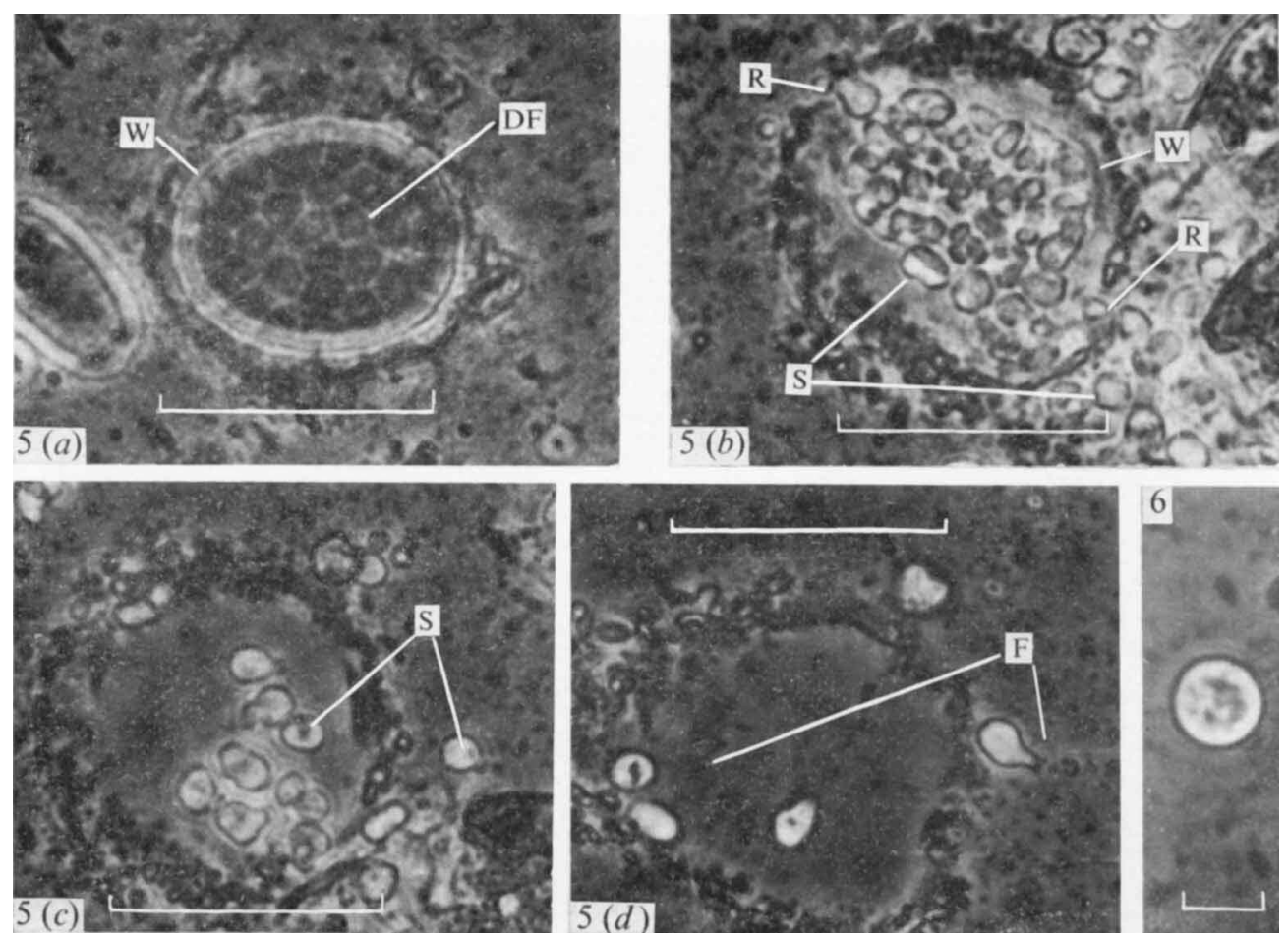

Fig. 5. Development of sporangium and liberation of $S$. communis flagellates, in a sample of rumen fluid incubated in vitro with inducer. Time after addition of inducer: (a) $45 \mathrm{~min}$; (b) $58 \mathrm{~min}$; (c) $60 \mathrm{~min}$; and (d) $65 \mathrm{~min}$. DF, developing sphaeromonas flagellates; W, sporangium wall; $\mathrm{R}$; ruptures in sporangium wall; $\mathrm{S}$, sphaeromonas flagellates; $\mathrm{F}$, flagellum. Bar marker $=50 \mu \mathrm{m}$.

Fig. 6. Sphaeromonas flagellate after the loss of the flagellum, $2 \mathrm{~h}$ after liberation from the sporangium. Bar marker $=10 \mu \mathrm{m}$.

flagellates were beginning to be liberated through at least two ruptures in the sporangium wall, which appears to have largely dissolved. Figure $5(c)(60 \mathrm{~min})$ and $(d)(65 \mathrm{~min})$ show the final stages of the release of flagellates. The initial egress of the flagellates was rapid, as though the interior of the sporangium was under pressure; frequently, a few cells became trapped for several minutes within the sporangium wall after the exit of the other cells (Fig. $5 d$ ). The maximum number of flagellates seen to be liberated from a sporangium was I I4. These observations showed that without doubt the sphaeromonas flagellates originated from a multiple reproductive body; differentiation of this body was stimulated by a dietary component, explaining the significant population density increase of the flagellates soon after the feeding of the host animal.

\section{Morphology and life-history}

Immediately after release from the sporangia present in FRF, the flagellates were usually irregularly shaped. Most became spherical within 2 to $3 \mathrm{~min}$, with an average diameter of $7.95 \mu \mathrm{m}(n=100)$, but a few remained elliptical and measured up to $10.5 \mu \mathrm{m}$ long. Each spore possessed one flagellum which averaged $24.9 \mu \mathrm{m}$ long $(n=100)$ and was posteriorly orientated when the cell was in motion. Within $30 \mathrm{~min}$ to $2 \mathrm{~h}$, the motility of the zoospores decreased and elliptical spores became spherical; movement eventually ceased, the flagellum became detached, and the refractivity of the cell increased. At this stage the non-motile cell 


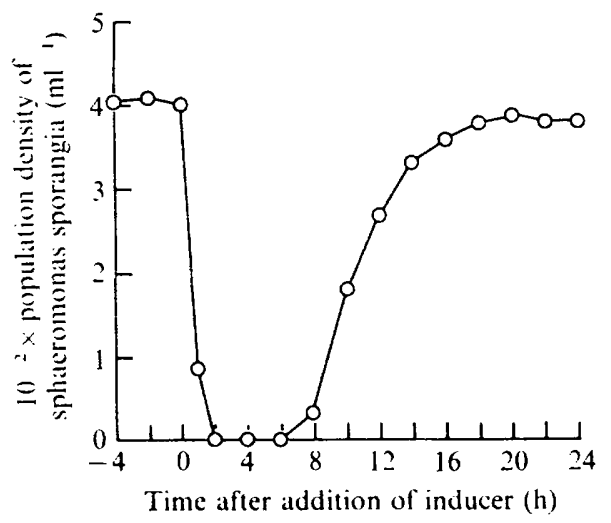

Fig. 7. Population density curve for sphaeromonas sporangia $>30 \mu \mathrm{m}$, after synchronous induction by the addition of inducer to the rumen at zero time. Average of three experiments.

(Fig. 6) was not distinguishable from that of Neocallimastix, although it was generally smaller. Because of this, the fate of Sphaeromonas in vivo, between 2 and $6 \mathrm{~h}$ after induction of sporogenesis in the presence of Neocallimastix, was not known; after $6 \mathrm{~h}$, however, the neocallimastix sporangia were sufficiently mature to be stimulated to differentiate and produce zoospores (Orpin, 1975). Since it was known that Neocallimastix sporulated within 15 to 30 min of induction and that sphaeromonas sporangia sporulated 45 to $90 \mathrm{~min}$ after exposure to the inducer in vitro in rumen fluid collected at least $6 \mathrm{~h}$ after feeding, it was possible to employ these differential induction rates to determine the population density of each type of sporangium. Figure 7 shows population density curves for sphaeromonas reproductive bodies ( $>30 \mu \mathrm{m}$ long) in vivo over a $24 \mathrm{~h}$ period, after synchronous induction using inducer extracted from $300 \mathrm{~g}$ oats.

Vegetative phase. Sporangia occurred in samples of rumen fluid which had been strained through one layer of muslin, both with and without a limited thallus consisting of a single, sometimes branched, rhizoid. It was not possible to determine whether the vegetative phase normally possessed a rhizoid, and whether those sporangia without one were merely those from which the rhizoid had been broken off in the rumen or during sample preparation. Rumen fluid that had not been filtered also contained forms without a rhizoid, indicating that the filtration stage was not necessarily responsible for all, if any, of the breakage of the halli. Only vegetative structures bearing a single sporangium have been identified in samples taken from the rumen, and when a rhizoid was present no penetration into plant material in the rumen fluid was observed. The large ( $>30 \mu \mathrm{m}$ long) sporangia were variable in shape, but were usually ovoid with maximum axial dimensions of $95 \times 64 \mu \mathrm{m}$. The thallus was sometimes branched, with maximum dimensions of $92 \times \mathrm{I} 4 \mu \mathrm{m}$.

Observations during culture in vitro. The sphaeromonas flagellates were morphologically identical with those observed in samples of rumen fluid, but the flagellum was retained during germination. Initial germination appeared to occur by an outgrowth of the cell, producing a thick (up to $8 \mu \mathrm{m}$ wide) rhizoid (Fig. 8). On this, up to seven spherical bodies of unknown function developed (Fig. 9), before the development of, usually, a single sporangium (Fig. 10); occasionally there were two or three sporangia. It was originally thought that the spherical bodies were sporangia from which flagellates had been released, but this seems unlikely since microscopic observation showed that the sporangium wall was extensively ruptured during the release of the flagellates and the walls of the spherical bodies appeared to be intact. 

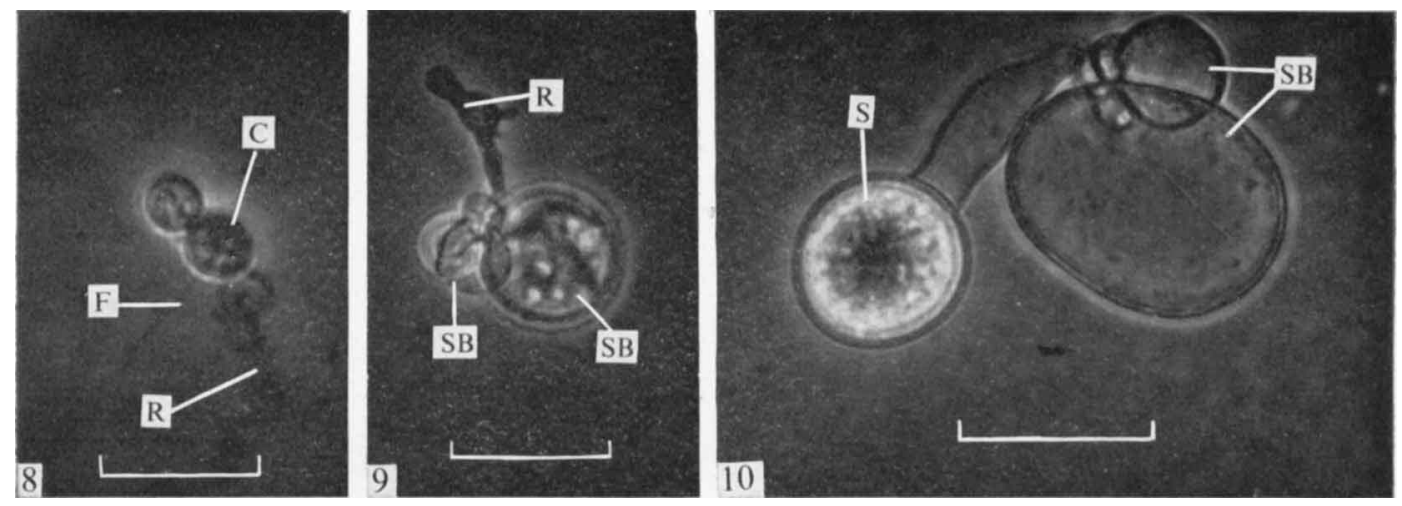

Fig. 8. Germination of Sphaeromonas communis flagellate in culture in vitro. F, flagellum; $\mathrm{R}$, rhizoid; $\mathrm{C}$, flagellate cell. Bar marker $=20 \mu \mathrm{m}$.

Fig. 9. Young vegetative stage of S. communis cultured in vitro. R, rhizoid; SB, spherical bodies of unknown function. Bar marker $=20 \mu \mathrm{m}$.

Fig. ro. Mature vegetative stage of $S$. communis cultured in vitro. S, sporangium; SB, spherical bodies. Bar marker $=50 \mu \mathrm{m}$.

\section{Effect of external conditions on sporogenesis}

Effect of concentration of inducer. Experiments conducted in vitro showed that the disappearance of all sphaeromonas sporangia and the maximum production of sphaeromonas flagellates could be achieved by the addition of inducer extracted from $40 \mathrm{mg}$ dry wt of oats/ml FRF. In later experiments, an excess of the inducer prepared from $0 \cdot 1 \mathrm{~g}$ dry wt of oats was used per ml FRF, except where the concentration of the inducer was critical.

Effect of storage of FRF. Storage of FRF at $39^{\circ} \mathrm{C}$ resulted in a rapid decrease in the ability of added inducer to stimulate the production of flagellates. Sphaeromonas flagellates produced by the same concentration of inducer after storage of FRF for various periods of time were [time of storage ( $\mathrm{min}$ ), and sphaeromonas flagellate population density compared with that produced at zero time (\%)] $0 \mathrm{~min}, 100 ; 30 \mathrm{~min}, 92 ; 60 \mathrm{~min}, 62 ; 90 \mathrm{~min}, 44 ; 120 \mathrm{~min}$, $20 ; 240 \mathrm{~min}$, I4. Increasing the concentration of the inducer by $400 \%$ did not result in increased flagellate production. The activity of the inducer was checked at each stage for its ability to induce flagellate production in sporangia in fresh rumen fluid, and was undiminished.

Effect of gas phase. Flagellates were released from the sporangia only in the presence of high carbon dioxide concentrations. The results were as follows [gas, and production of flagellates compared with those produced under standard conditions (\%)] in $\mathrm{O}_{2}$-free $\mathrm{CO}_{2}$, I00; in $5 \% \mathrm{CO}_{2}+95 \% \mathrm{~N}_{2}$, I0; in air, o. Oxygen-free $\mathrm{CO}_{2}$ was then bubbled through tubes containing either $95 \% \mathrm{~N}_{2}+5 \% \mathrm{CO}_{2}, \mathrm{~N}_{2}$, or air for $2 \mathrm{~min}$, the tubes were stoppered and incubated for a further $60 \mathrm{~min}$, and the sphaeromonas flagellates counted. The total flagellate production ( $\%$ ) was as follows in $95 \% \mathrm{~N}_{2}+5 \% \mathrm{CO}_{2}, 85$; in $\mathrm{N}_{2}, 78$; in air, 0 . This indicated that although little flagellate production occurred in the presence of nitrogen or air, air was toxic, while nitrogen alone merely inhibited sporulation; $95 \% \mathrm{~N}_{2}+5 \% \mathrm{CO}_{2}$ produced little sporulation, but at high $\mathrm{CO}_{2}$ levels sporulation was high.

Effect of $p H$. The $\mathrm{pH}$ of the FRF used had little effect between $\mathrm{pH} 6.5$ and $\mathrm{pH} 7.5$ on the number of flagellates produced ( $\mathrm{pH}$, and percentage of sphaeromonas flagellates produced) $5 \cdot 5,24 ; 6 \cdot 0,82 ; 6 \cdot 5,100 ; 7 \cdot 0,85 ; 7 \cdot 5,52 ; 8 \cdot 0,32$. 


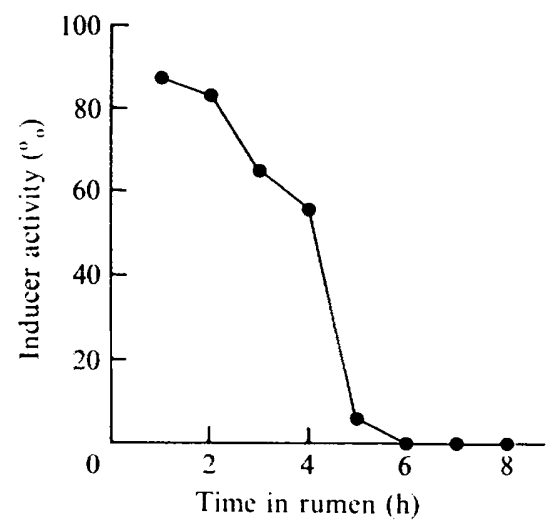

Fig. 11 . The presence of active inducer in the rumen after feeding of the host sheep. Samples ( $50 \mathrm{ml})$ of rumen fluid were taken at timed intervals after feeding, cooled to $4 \mathrm{C}$ and strained through one layer of muslin; the particulate material retained was washed with $50 \mathrm{ml}$ water. Inducer was extracted from the CFP fraction as described in the text and assayed in vitro for the liberation of sphaeromonas flagellates from sporangia present in fresh rumen fluid. The activity of the inducer present in $0.1 \mathrm{~g}$ dry wt LP is expressed as a percentage of sphaeromonas liberated by inducer extracted from $0 . \mathrm{I} g$ dry wt oats, when incubated with another sample of the same rumen fluid. Average of four experiments.

Effect of temperature. Sphaeromonas flagellate production occurred only over the temperature range of 36 to $45^{\circ} \mathrm{C}$, with a maximum at $39^{\circ} \mathrm{C}$. Results were as follows, given as a percentage of those flagellates produced at $39^{\circ} \mathrm{C}: 25^{\circ} \mathrm{C}, 0 ; 30{ }^{\circ} \mathrm{C}, 0 ; 36{ }^{\circ} \mathrm{C}, 13 ; 39^{\circ} \mathrm{C}$, $100 ; 42{ }^{\circ} \mathrm{C}, 86 ; 45^{\circ} \mathrm{C}, 10 ; 50{ }^{\circ} \mathrm{C}$, o. No preduction of sphaeromonas flagellates at temperatures above $45^{\circ} \mathrm{C}$ or below $36^{\circ} \mathrm{C}$ occurred, even if the time of incubation was increased to $2 \mathrm{~h}$.

\section{Environmental examination}

No sphaeromonas flagellates were observed in the samples of food, water or litter examined.

\section{Occurrence of the inducer in rumen}

The CFP fraction contained active inducer until $5 \mathrm{~h}$ after the commencement of feeding by the host (Fig. I1).

\section{DISCUSSION}

These results show that the rumen flagellate Sphaeromonas communis may not be of protozoal origin as suggested by Braune (1913), but may be fungoid in nature. Although many flagellate protozoa possess reproductive bodies similar to fungal sporangia (Kudo, 1954), the possession of a rhizoid by some of the sporangia which subsequently developed to produce sphaeromonas flagellates indicated that the organism is probably not a species of flagellate protozoon. Fungi whose vegetative phase comprise a thallus consisting of a simple hypha or rhizoid bearing sporangia in which posteriorly uniflagellated cells (zoospores) develop are placed in the aquatic Phycomyces (Sparrow, 1960). Sphaeromonas communis possesses these characteristics and may therefore be a member of this family. Detailed examination of both stages in the life-history of Sphaeromonas is necessary before any conclusions regarding the taxonomic position of the organism can be drawn.

The life-history of $S$. communis appears to be similar to that of the rumen flagellate $N$. frontalis (Orpin, 1975), but the two species are probably unrelated because of the differing morphology of their flagellate and vegetative stages. The flagellates of $S$. communis 
are uniflagellate; those of $N$. frontalis are multiflagellate, with up to I4 flagella forming a single locomotory organelle. Like the flagellate of $N$. frontalis, that of $S$. communis lost its motility within a relatively short time ( 2 to $3 \mathrm{~h}$ ) after being released from the sporangium, and germinated to produce the vegetative phase. The development of the sphaeromonas flagellate into the thallus has not been observed in samples of rumen fluid, but since the possession of a rhizoid may not be obligatory for growth of the sporangium (only $25 \%$ of mature sporangia in rumen fluid samples possess a rhizoid or show evidence that a rhizoid was originally present, but broken during preparation) it seems likely that some of the flagellates develop into the sporangium without prior formation of a rhizoid. In vitro, the flagellate germinated to produce a rhizoid on which the sporangium was borne, and usually a second spherical-to-ovoid structure of unknown function which may have been produced in response to the constituents of the culture medium.

The sporangia of $S$. communis were induced to differentiate and liberate flagellates in response to a component in the diet of the host animal. The response was slower than that shown by $N$. frontalis (Orpin, I975), with peak production of flagellates in vivo occurring I $h$ after the commencement of feeding, compared with 15 to 20 min after feeding commenced in the case of Neocallimastix. This differing rate of zoospore production was used to differentiate between the sporangia of Neocallimastix and Sphaeromonas in vitro; it was not possible to differentiate between them by direct microscopy.

The nature of the dietary inducer of sporogenesis is under investigation. Inducer disappeared from the rumen within 4 to $5 \mathrm{~h}$ of feeding. However, at any time during the day, sphaeromonas flagellates could be found in the rumen. Since the flagellates survived only for 2 to $3 \mathrm{~h}$ their presence after the inducer disappeared suggested that there was a second factor stimulating sporogenesis, independent of the time of feeding of the host animal. This factor is probably active during culture in vitro, for the culture medium was devoid of inducer.

The optimum conditions for the genesis and liberation of flagellates $\left(\mathrm{pH} 6.5 ; 39{ }^{\circ} \mathrm{C}\right.$; presence of $\mathrm{CO}_{2}$ ) were similar to those prevailing in the rumen (Hungate, I966); this, together with the absence of the flagellates from the immediate external environment and their frequent appearance in the rumen of the host, indicated that they are true rumen inhabitants and not organisms acquired adventitiously.

Two species of phycomycete fungi are known to occur in the rumen (Lubinsky, 1955 $a, b$ ). These are parasitic within ciliate protozoa, but their dispersal stage has not been determined. Zoospores present within sporangia inside the ciliates are aflagellate, and considerably smaller (I.5 $5 \mathrm{~m}$ diameter for Sphaerita hoari, parasitizing Eremoplastron bovis; 3 to $7 \mu \mathrm{m}$ long by $\mathrm{I}^{\cdot} 5 \mu \mathrm{m}$ wide for Saggitospora cameroni, parasitizing Eudiplodinium magii) than those of the non-parasitic $S$. communis (average diameter $7 \cdot 45 \mu \mathrm{m})$ or $N$. frontalis $(20.6 \times 8.7 \mu \mathrm{m})$ (Orpin, 1975). The vegetative stages of Sphaerita and Saggitospora occur within the ciliates, and therefore could not be confused with the vegetative stages of either Neocallimastix or Sphaeromonas which are free within the rumen fluid.

\section{REFERENCES}

Abou Akmada, A. R., Bartley, E. E., Berube, R., Fina, L. R., Meyer, R. M., Hendricks, D. \& Julius, F. (I968). Simple method to remove completely ciliate protozoa from adult ruminants. Applied Microbiology 16, 1475-1477.

BeCKeR, E. R. \& TALbot, M. (1927). The protozoan fauna of the rumen and reticulum of American cattle. Iowa State College Journal of Science $1,345-365$.

Braune, R. (1913). Untersuchungen über die im Wiederkäuermagen vorkommenden Protozoen. Archiv für Protistenkunde 32, I I I-I 70. 
Das Gupta, M. (1935). Preliminary observations on the protozoan fauna of the Indian goat, Capra hirens Linn. Archiv fiir Protistenkunde 85, I 53-172.

Hungate, R. E. (1966). The Rumen and its Microbes. New York: Academic.

Jensen, E. A. \& HAMmond, D. M. (1964). A morphological study of trichomonads and related flagellates from the bovine digestive tract. Journal of Protozoology Ir, 386-394.

KuDo, R. R. (1954). Protozoology, 4th edn. Springfield, Illinois: Thomas.

Levine, N. D. (196I). Protozoan Parasites of Domestic Animals and of Man. Minneapolis: Burgess Publishing.

Liebetanz, E. (1910). Die parasitischen Protozoen des Widerkäuermagens. Archiv für Protistenkunde 19, 19.

LUBINSKY, G. (1955a). On some parasites of parasitic protozoa. I. Sphaerita hoari, sp.n. - a chytrid parasitising Eremoplastron bovis. Canadian Journal of Microbiology $1,440-450$.

LUBINSKY, G. (IS55b). On some parasites of parasitic protozoa. II. Saggitospora cameroni gen. n., sp.n. - a phycomycete parasiting Ophryoscolecidae. Canadian Journal of Microbiology I, 675-684.

ORPIN, C. G. (1974a). The rumen flagellate Callimastrix frontalis: does sequestration occur? Journal of General Microbiology 84, 395-398.

ORPIN, C. G. (1974b). The rumen flagellates Callimastix frontalis and Monas comumnis - zoospores of Phycomycete fungi. Journal of Applied Bacteriology 37(4), ix-x.

ORPIN, C. G. (1975). Studies on the rumen flagellate Neocallimastix frontalis. Journal of General Microbiology 91, 249-262

Sparrow, F. K., JR (1960). Aquatic Phycomycetes, 2nd edn. Ann Arbor: University of Michigan Press.

WARNER, A. C. I. (1966). Diurnal changes in the concentrations of micro-organisms in the rumens of sheep fed limited diets once daily. Journal of General Microbiology 45, 21 3-235.

WenYon, C. M. (1926). Protozoology. New York: William Wood. 